\title{
ПСИХОФАРМАКОТЕРАПИЯ
}

\author{
УДК 616.895.8:615.214:615.869:575.174.015.3:632.95.025
}

Для цитирования: Зубов Д.С., Иванов М.В., Хальчицкий С.Е., Согоян М.В., Щедрина Л.В. Взаимосвязь полиморфизма гена rs6265 и сывороточного уровня BDNF у пациентов с терапевтически резистентной шизофренией в динамике лечебного процесса. Сибирский вестник психиатрии и наркологии. 2020; 2 (107): 60-66. https://doi.org/10.26617/1810-3111-2020-2(107)-60-66

\section{Взаимосвязь полиморфизма гена rs6265 и сывороточного уровня BDNF у пациентов с терапевтически резистентной шизофренией в динамике лечебного процесса}

\author{
13убов Д.С., ${ }^{1}$ Иванов М.В., ${ }^{2}$ Хальчицкий С.Е.,

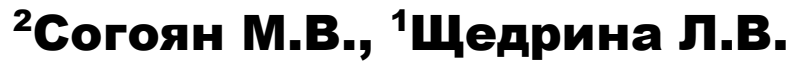 \\ ${ }^{1}$ Нацииональный медицинский исследовательский центр психиатрии и неврологии им. В.М. Бехтерева \\ Россия, 192019, Санкт-Петербург, ул. Бехтерева, 3 \\ ${ }^{2}$ Научно-исследовательский детский ортопедический институт имени Г.И. Турнера \\ Россия, 196603, Санкт-Петербург, Пушкин, Парковая ул., д. 64-68
}

\begin{abstract}
PEЗЮME
В статье приводятся данные об обнаруженной взаимосвязи полиморфизма rs6265 гена BDNF, сывороточного уровня BDNF и клинико-терапевтических показателей у больных параноидной шизофренией с наличием терапевтической резистентности. Объектом исследования являлись пациенты с диагностированной параноидной шизофренией, разделенные на две группы согласно характеру интервенций: сочетание электросудорожной терапии с психофармакотерапией (ЭСТ+ПФТ) и исключительно ПФТ. Результаты проведенного исследования свидетельствуют о достоверно более высоком терапевтическом ответе и более выраженной редукции психопатологической симптоматики у пациентов группы сочетанной терапии (ЭСТ+ПФТ). Одновременно было установлено, что сывороточный уровень BDNF имел тенденцию к большему увеличению при использовании сочетанного варианта терапии (ЭСТ+ПФТ), главным образом у больных с генотипами ValMet и MetMet. Полученные первоначальные результаты будут уточнены в дальнейшем при проведении последующих более масштабных исследований.
\end{abstract}

Ключевые слова: нейротрофический фактор мозга BDNF, rs6265 Val66Met, электросудорожная терапия (ЭСТ), психофармакотерапия, терапевтически резистентная шизофрения, терапевтическая резистентность, шкала PANSS.

\section{АКТУАЛЬНОСТЬ ИССЛЕДОВАНИЯ}

Шизофрения относится к одному из основных инвалидизирующих психических расстройств с частотой встречаемости в европейской популяции от 0,6 до 0,8\% [1]. Социальноэкономический аспект - не единственный компонент бремени этой болезни, поскольку немаловажными остаются и её клинические аспекты, в первую очередь вопросы терапевтической резистентности. Так, количество пациентов, не реагирующих на стандартные терапевтические тактики, иными словами, обнаруживающих проявления терапевтической резистентности, варьирует от 30 до 60\% от общего числа больных шизофрений [2]. Не вызывает сомнения, что сложившаяся ситуация во многом связана с недостаточной изученностью патогенеза как основного заболевания, так и терапевтической резистентности в частности. Одной из современных гипотез развития шизофренического процесса является «нейротрофиновая гипотеза», постулирующая о том, что изменения в головном мозге при шизофрении являются результатом нейроонтогенеза, протекающего с участием белков-нейротрофинов, влияющих на основные функции ЦНС [3, 4, 5, 6]. Наиболее изучаемым представителем нейротрофинов является мозговой нейротрофический фактор BDNF, непосредственно связываемый с процессами роста и дифференциации нейронов, нейротрансмиссией, нейропластичностью и регуляцией процессов апоптоза $[7,8,9,10]$. 
Согласно данным литературы, пациенты, страдающие шизофренией, имеют более низкий сывороточный уровень BDNF и количество BDNF-позитивных нейронов в отличие от здоровых лиц, причем у пациентов с терапевтический резистентностью он может быть снижен в ещё большей степени $[5,11]$. Одним из потенциальных факторов вовлеченности BDNF в патологические процессы считается полиморфизм BDNF rs6265 (Val66Met) [12, 13]. По данным литературы, замещение аллелей, кодирующих экспрессию BDNF, может приводить к нарушению его синтеза $[12,13,14]$. Влияние различных методов лечения на уровень BDNF описывается как один из потенциальных патогенетических механизмов, в том числе и из-за заметной роли данного белка в усилении синаптической активности $[5,15,16]$.

Сохраняющим актуальность методом лечения резистентных состояний при шизофрении остается электросудорожная терапия (ЭСТ), механизм действия которой также потенциально связывается с активацией синтеза BDNF [17, $18,19]$. Несмотря на свою высокую эффективность и безопасность, ЭСТ является высоко стигматизированным методом, в том числе и из-за незначительного количества отечественных работ, объективизирующих её использование.

Настоящая публикация включает материалы работы, которые дают возможность провести изучение взаимосвязи между полиморфизмом BDNF rs6265, сывороточным уровнем биомаркера и результатами, полученными при использовании двух вариантов противорезистентных воздействий терапевтической ЭСТ у больных шизофренией.

\section{ЦЕЛЬ ИССЛЕДОВАНИЯ}

1. Оценка эффективности использования комбинированной электросудорожной и психофармакотерапии в сравнении с лекарственной терапией у пациентов с терапевтически резистентной шизофренией.

2. Анализ частоты встречаемости полиморфных аллелей rs6265 гена BDNF у пациентов с терапевтически резистентной шизофренией.

3. Определение зависимости характера терапевтического ответа от полиморфизма BDNF rs6265.

4. Оценка сывороточного уровня BDNF у пациентов с различными аллелями полиморфизма BDNF rs6265 в зависимости от проводимой противорезистентной терапии.

\section{МАТЕРИАЛЫ И МЕТОДЫ}

Набор клинического материала производился на базе отделения биологической терапии ФГБУ «НМИЦ ПН им В.М. Бехтерева» Минздрава России.

Критериями включения пациентов в исследование являлись: возраст 18-60 лет, европеоидная раса, диагноз «параноидная шизофрения» в соответствии с критериями рубрики F20.0 по МКБ-10, наличие терапевтической резистентности к психотропным лекарственным методам лечения. Критериями исключения служили: возраст до 18 лет и старше 60 лет, отказ пациента от участия в исследовании и проведении курса сеансов ЭСТ, выявленная при помощи ЭЭГ пароксизмальная активность, наличие тяжелой соматической патологии острой/хронической или в стадии обострения.

Терапевтическая резистентность устанавливалась на основании актуальных международных критериев, согласно которым психическое состояние пациента характеризовалось незначительным снижением тяжести продуктивных психопатологических расстройств или полным отсутствием положительной динамики после последовательного лечения двумя и более антипсихотиками различных фармакологических групп в течение 6-8 недель в среднетерапевтических или максимально допустимых дозировках [20].

Все пациенты (76 человек, из них 47 мужчин и 29 женщин) были разделены на сопоставимые по терапевтическим показателям группы: ЭСТ+ПФТ (57 человек) - пациенты, получавшие комбинированную электросудорожную и психофармакологическую терапию; ПФТ (19 человек) - пациенты, получавшие только медикаментозную терапию психотропными лекарственными средствами. Средний возраст пациентов составлял $31,4 \pm 7,6$ года, средняя длительность заболевания - 6,4 44,9 года. В процессе терапии в обеих группах наблюдения наиболее часто применялись антипсихотические препараты типичного ряда: галоперидол $(29,5 \pm 13,38$ мг/сут) и клопиксол $(47,22 \pm 41,62$ мг/сут). Из препаратов атипичного ряда у больных основной и контрольной групп использовались оланзапин $(22,50 \pm 6,38$ мг/сут), кветиапин $(500 \pm 216$ мг/сут), арипипразол $(27,4 \pm 4,87$ мг/сут), палиперидон $\quad(9,71 \pm 1,99$ мг/сут), клозапин $(212,92 \pm 192,43$ мг/сут). У пациентов основной группы, согласно современным рекомендациям, лекарственная нагрузка на фоне проведения процедур ЭСТ снижалась. 
Процедуру ЭСТ выполняли с согласия пациента, после проведения исключавшего противопоказания стандартизированного обследования, положительного решения клиникоэкспертной комиссии, по современной модифицированной методике в присутствии врача анестезиолога-реаниматолога. Анестезиологическое пособие включало в себя внутривенное введение раствора атропина сульфата $(0,1 \%$ $0,5)$, раствора пропофола $(1 \%-1,0)$ в дозах 150-200 мг на фоне миорелаксации раствором суксаметония йодида (дитилин $2 \%-1,0$ ) в дозе 160-190 мг.

Для проведения ЭСТ применялся аппарат «ЭСТЕР». Параметры электрической стимуляции подбирались индивидуально, однако у большинства пациентов использовались референсные значения, заданные производителем. Частота следования импульсов устанавливалась в диапазоне 27 Гц, длительность импульсов составляла 0,5-1,0 мс при амплитуде 550-850 мА. Состоявшимся считался генерализованный тонико-клонический судорожный приступ длительностью более 30 секунд. Среднее количество выполненных процедур составляло $11 \pm 3,4$.

Взятие биологических образцов (венозная кровь) и клинико-шкальная оценка состояния пациентов с использованием стандартизированной шкалы PANSS [21] проводились двукратно: 1) на этапе включения в исследование, 2) на этапе окончания процедур ЭСТ (через 4 недели терапии) и в идентичные временные промежутки для пациентов группы ПФТ. Значимым терапевтическим ответом считалась редукция общего балла по шкале PANSS более 20\%. Пациенты с таким показателем были от- несены к «респондерам», с редукцией менее $20 \%$ - к «нонреспондерам» [22].

Для определения концентрации биологических показателей в сыворотке крови использовался метод иммуноферментного анализа (ИФА) при помощи наборов фирмы «R\&DSystems» (США). Генотипирование полиморфизма гена BDNF rs6265 (Val66Met) проводилось с помощью метода полимеразной цепной реакции в реальном времени (ПЦР-РВ) диагностическим набором производства ООО «НПФ Синтол».

Обработка полученного клинического материала проводилась на основе использования программного пакета SPSS Statistics. Применялись следующие методы статистической обработки: U-критерий Манна-Уитни, t-критерий Стьюдента, Т-критерий Вилкоксона.

\section{РЕЗУЛЬТАТЫ}

На начальном этапе включения в исследование все пациенты находились в остром психотическом состоянии. Значение общего балла по шкале PANSS у пациентов из группы сочетанной терапии (ЭСТ+ПФТ) было незначительно выше и составляло $114,90 \pm 7,39$ балла против $114,05 \pm 3,69$ балла для пациентов группы ПФТ. Выраженность позитивной $(П)$, негативной $(\mathrm{H})$ и общей психопатологической $(\mathrm{O})$ симптоматики характеризовалась следующими значениями. Позитивная симптоматика: ЭСТ+ПФТ $26,52 \pm 10,56$ балла, ПФТ - 25,85 $\pm 4,95$ балла. Негативная симптоматика: ЭСТ +ПФТ -

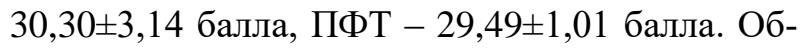
щая психопатологическая симптоматика: ЭСТ+ПФТ - 58,08 $\pm 6,92$ балла, ПФТ $58,71 \pm 3,76$ балла. Различия между группами на начальном этапе исследования не достигали статистической значимости (p>0,05) (табл. 1).

Т а б л и ц а 1. Оценка актуального психического состояния пациентов обследованных групп по шкале PANSS (в баллах)

\begin{tabular}{|l|c|c|c|c|c|c|}
\hline \multirow{2}{*}{ Показатель по шкале PANSS } & \multicolumn{2}{|c|}{ При включении в исследование } & \multicolumn{3}{|c|}{ Через 4 недели терапии } \\
\cline { 2 - 8 } & ЭСТ+ПФТ & ПФТ & $\mathrm{p}$ & ЭСТ+ПФТ & ПФТ & $\mathrm{p}$ \\
\hline Позитивная симптоматика (П) & $26,52 \pm 10,56$ & $25,85 \pm 4,95$ & $>0,05$ & $14,90 \pm 5,53$ & $22,25 \pm 4,55$ & $<0,001$ \\
\hline Негативная симптоматика (Н) & $30,30 \pm 3,14$ & $29,49 \pm 1,01$ & $>0,05$ & $20,42 \pm 2,94$ & $26,98 \pm 0,82$ & $<0,001$ \\
\hline $\begin{array}{l}\text { Общая психопатологическая } \\
\text { симптоматика (О) }\end{array}$ & $58,08 \pm 6,92$ & $58,71 \pm 3,76$ & $>0,05$ & $35,49 \pm 4,32$ & $52,11 \pm 3,61$ & $<0,001$ \\
\hline Общий балл по шкале & $114,90 \pm 7,39$ & $114,05 \pm 3,69$ & $>0,05$ & $70,81 \pm 4,84$ & $101,34 \pm 3,54$ & $<0,001$ \\
\hline
\end{tabular}

Через 4 недели терапии у больных обеих групп отмечалась статистически значимая положительная динамика по основным психопатологическим паттернам шкалы PANSS $(\mathrm{p} \leq 0,001)$. При это более выраженная редукция позитивной, негативной и общей психопатоло- гической симптоматики выявлялась у пациентов группы сочетанной терапии (ЭСТ +ПФТ). Различия между группами на заключительном этапе исследования были статистически значимы и характеризовались следующим образом. Позитивная симптоматика: ЭСТ+ПФТ - 
$14,90 \pm 5,53$ балла, ПФТ - 22,25 $\pm 4,55$ балла. Негативная симптоматика: ЭСТ+ПФТ $20,42 \pm 2,94$ балла, ПФТ - 26,98 $\pm 0,82$ балла. Общая психопатологическая симптоматика: ЭСТ+ПФТ - 35,49 $\pm 4,32$ балла, ПФТ $52,11 \pm 3,61$ балла $(\mathrm{p} \leq 0,001)$.

Общий балл по шкале PANSS у пациентов из группы сочетанной терапии (ЭСТ+ПФТ) составлял $70,81 \pm 4,84$ балла и $101,34 \pm 3,54$ балла у пациентов, получавших только ПФТ $(\mathrm{p} \leq 0,001)$. Редукция позитивной симптоматики по шкале PANSS составила $43,82 \%$, негативной - $32,60 \%$, общей психопатологической $38,89 \%$, общего балла $-38,37 \%$. В то время как аналогичные показатели редукции позитивной симптоматики для группы больных, получавших ПФТ, составляли $13,92 \%$, негативной симптоматики $-8,51 \%$, общей психопатологической симптоматики - 11,24\%, общий балл $11,14 \%$ соответственно.

При генотипировании пациентов было обнаружено, что аллель Val гена BDNF rs6265 встречается с более высокой частотой: 77,6\% гомозиготный генотип GG (ValVal), 19,8\% гетерозиготный генотип GA (ValMet), 2,6\% гомозиготный генотип AA (MetMet), что согласуется с опубликованными в литературе данными. При этом нами не было выявлено статистически значимых достоверных различий по частоте встречаемости различных вариантов полимофризма BDNF rs6265 как в общей выборке обследованных пациентов, так и между группами больных, включенных в исследование ( $\mathrm{p}>0,05)$ (табл. 2).

T а б л и ц а 2. Частота встречаемости аллельных вариантов полиморфизма BDNF rs6265 у пациентов обследованных групп (в аб́с. цифрах и процентах)

\begin{tabular}{|l|c|c|c|c|c|c|c|}
\hline \multirow{2}{*}{ Группа пациентов } & \multicolumn{2}{|c|}{ GG (ValVal) } & \multicolumn{2}{c|}{ GA (ValMet) } & \multicolumn{2}{c|}{ AA (MetMet) } & Уровень досто- \\
\cline { 2 - 7 } & $\mathrm{N}$ & $\%$ & $\mathrm{n}$ & $\%$ & $\mathrm{n}$ & $\%$ & \multicolumn{1}{c|}{ верности (p) } \\
\hline Общая выборка $(\mathrm{n}=76)$ & 59 & 77,6 & 15 & 19,8 & 2 & 2,6 & $>0,05$ \\
\hline ЭСТ+ПФТ $(\mathrm{n}=57)$ & 45 & 79 & 10 & 17,5 & 2 & 3,5 & $>0,05$ \\
\hline ПФТ $(\mathrm{n}=19)$ & 14 & 73,7 & 5 & 26,3 & 0 & 0 & $>0,05$ \\
\hline
\end{tabular}

Как продемонстрировано в таблице 3, нами не было установлено взаимосвязи между характером терапевтического ответа пациентов и различием встречаемости аллелей гена BDNF rs6265 как у пациентов, относимых к группе «респондеров», так и к группе «нонреспондеров».
Общее количество пациентов, ответивших на терапию (редукция общего балла превышала $20 \%$ по шкале PANSS) составляло 55 человек (72,4\%). В группе ЭСТ+ПФТ к «респондерам» относился 51 пациент $(89,5 \%)$, в то время как в группе ПФТ этим критериям полноценно отвечали лишь 4 пациента $(21,1 \%)$.

T а б л и ц а 3. Характер редукции психопатологической симптоматики по шкале PANSS в зависимости от аллельных вариантов полиморфизма гена BDNF rs6265 (в процентах)

\begin{tabular}{|c|c|c|c|c|c|c|c|c|c|c|c|c|c|}
\hline \multirow{3}{*}{ Группа пациентов } & \multicolumn{4}{|c|}{ GG (ValVal) } & \multicolumn{4}{|c|}{ GA (ValMet) } & \multicolumn{4}{|c|}{ AA (MetMet) } & \multirow{3}{*}{$\begin{array}{l}\text { Уровень до- } \\
\text { стоверности } \\
\text { (p) }\end{array}$} \\
\hline & \multicolumn{2}{|c|}{ Респ. } & \multicolumn{2}{|c|}{ Нонресп. } & \multicolumn{2}{|c|}{ Респ. } & \multicolumn{2}{|c|}{ Нонресп. } & \multicolumn{2}{|c|}{ Респ. } & \multicolumn{2}{|c|}{ Нонресп. } & \\
\hline & $\mathrm{N}$ & $\%$ & $\mathrm{n}$ & $\%$ & $\mathrm{n}$ & $\%$ & $\mathrm{n}$ & $\%$ & $\mathrm{n}$ & $\%$ & $\mathrm{n}$ & $\%$ & \\
\hline & 44 & 57,9 & 15 & 19,7 & 9 & 11,8 & 6 & 7,9 & 2 & 2,6 & & -1 & $>0,05$ \\
\hline ЭСТ & 40 & 70,2 & 5 & 8,8 & 9 & 15,8 & 1 & 1,76 & 2 & 3,5 & 0 & & 0,05 \\
\hline ПФТ (n=19) & 4 & 21,1 & 10 & 52,6 & 0 & 0 & 5 & 26,3 & 0 & 0 & 0 & 0 & $>0,05$ \\
\hline
\end{tabular}

Анализ сывороточного уровня BDNF на начальном этапе исследования продемонстрировал схожие значения концентрации данного биомаркера не только в общей выборке, но и при групповом разделении пациентов. Показатели в общей выборке имели следующие значения: $\quad 10,80 \pm 5,60$ нг/мл, ЭСТ + ПТ $10,89 \pm 6,13$ нг/мЛ, ПФТ - 10,49 $\pm 3,35$ нг/мЛ (табл. 4).

При оценке динамики уровня BDNF, выполненной повторно (через 4 недели терапии), бы- ло выявлено, что у пациентов из группы сочетанной терапии (ЭСТ $+П Ф Т)$ на уровне тенденции имело место более выраженное повышение значений сывороточной концентрации BDNF $(11,85 \pm 7,29$ нг/мЛ - ЭСТ +ПФТ, $10,10 \pm 4,79$ нг/мл - ПФТ). Заметный эффект повышения уровня BDNF после 4 недель терапии наблюдался в группе ЭСТ+ПФТ у больных с генотипом MetMet (рост показателя от $11,15 \pm 10,85$ до $15,77 \pm 13,89$ нг/мл), однако эти данные имели характер тенденции ( $>>0,05)$. 
T а б л и ц а 4. Динамика сывороточного уровня BDNF в зависимости от аллельных вариантов полиморфизма BDNF rs6265 у обследованных пациентов (нг/мл)

\begin{tabular}{|c|c|c|c|c|c|c|c|c|c|}
\hline \multirow[b]{2}{*}{ Группа пациентов } & \multicolumn{4}{|c|}{ При включении в исследование } & \multicolumn{4}{|c|}{ Через 4 недели терапии } & \multirow{2}{*}{$\begin{array}{l}\text { Уровень } \\
\text { достовер- } \\
\text { ности (p) }\end{array}$} \\
\hline & $\begin{array}{l}\text { Общий } \\
\text { уровень }\end{array}$ & $\begin{array}{c}\text { GG } \\
\text { (ValVal) }\end{array}$ & $\begin{array}{c}\text { GA } \\
\text { (ValMet) }\end{array}$ & $\begin{array}{c}\text { AA } \\
\text { (MetMet) }\end{array}$ & $\begin{array}{l}\text { Общий } \\
\text { уровень }\end{array}$ & $\begin{array}{c}\mathrm{GG} \\
(\mathrm{ValVal})\end{array}$ & \begin{tabular}{|c|} 
GA \\
(ValMet)
\end{tabular} & $\begin{array}{c}\text { AA } \\
\text { (MetMet) }\end{array}$ & \\
\hline $\begin{array}{l}\text { Общая выборка } \\
(\mathrm{n}=76)\end{array}$ & $\begin{array}{c}10,80 \pm \\
5,60 \\
\end{array}$ & $\begin{array}{c}10,72 \pm \\
5,37 \\
\end{array}$ & $\begin{array}{c}11,06 \pm \\
6,73 \\
\end{array}$ & $\begin{array}{c}11,15 \pm \\
10,85 \\
\end{array}$ & $\begin{array}{c}11,45 \pm \\
6,81 \\
\end{array}$ & $\begin{array}{c}11,25 \pm \\
6,68 \\
\end{array}$ & \begin{tabular}{|c|}
$12,20 \pm$ \\
7,12 \\
\end{tabular} & \begin{tabular}{|c|}
$15,77 \pm$ \\
13,89 \\
\end{tabular} & $>0,05$ \\
\hline ЭСТ +ПФТ (n=57) & $\begin{array}{c}10,89 \pm \\
6,13 \\
\end{array}$ & $\begin{array}{c}10,71 \pm \\
5,78\end{array}$ & $\begin{array}{c}11,55 \pm \\
7,9 \\
\end{array}$ & $\begin{array}{c}11,15 \pm \\
10,85 \\
\end{array}$ & $\begin{array}{c}11,85 \pm \\
7,29 \\
\end{array}$ & $\begin{array}{c}11,45 \pm \\
7,41 \\
\end{array}$ & $\begin{array}{c}12,94 \pm \\
7,35 \\
\end{array}$ & $\begin{array}{c}15,77 \pm \\
13,89 \\
\end{array}$ & $>0,05$ \\
\hline ПФТ (n=19) & $\begin{array}{c}10,49 \pm \\
3,35\end{array}$ & $\begin{array}{c}11,66 \pm \\
3,14\end{array}$ & $\begin{array}{c}9,83 \pm \\
2,45\end{array}$ & - & $\begin{array}{c}10,10 \pm \\
4,79\end{array}$ & $\begin{array}{c}9,76 \pm \\
3,03\end{array}$ & $\begin{array}{c}10,34 \pm \\
7,15\end{array}$ & - & $>0,05$ \\
\hline
\end{tabular}

\section{ВЫВОДЫ}

При наличии проявлений терапевтической резистентности у больных шизофренией электросудорожная терапия в сочетании с психофармакотерапией обладает большей клинической эффективностью (редукция психопатологической симптоматики более $20 \%$ по шкале PANSS) в сравнении с терапией исключительно психотропными лекарственными средствами (редукция составляет менее 20\% по PANSS).

У исследованных больных с терапевтически резистентной шизофренией обнаружена сопряженность между показателями терапевтического ответа на противорезистентные воздействия и выявленной динамикой уровня BDNF в процессе лечения.

Обнаружена тенденция к росту сывороточного уровня BDNF при использовании сочетания электросудорожной и психофармакотерапии, в особенности у пациентов с генотипами MetMet и ValMet полиморфизма rs6265 гена $\mathrm{BDNF}$, что не определялось при использовании только лекарственной терапии. Эти первоначально установленные данные, вероятно, могут свидетельствовать о вовлеченности BDNF в механизм терапевтического действия ЭСТ.

Принимая во внимание установленное отсутствие достоверно значимой взаимосвязи между характером терапевтического ответа пациентов и исследованными аллелями полиморфизма BDNF rs6265, нам представляется возможным предположить, что BDNF проявляет свое участие в процессе лечения исключительно во взаимодействии с другими биологическими патогенетическими субстанциями. Тем самым приведенные в статье результаты имеют характер предварительных исследований и указывают на целесообразность дальнейшего уточнения с использованием не единичного полиморфизма, а охватом более широкого спектра биологических маркеров, на большей выборке пациентов.

\section{КОНФЛИКТ ИНТЕРЕСОВ}

Авторы заявляют об отсутствии актуального и потенциального конфликта интересов в связи с публикацией данной статьи.

\section{ИСТОЧНИК ФИНАНСИРОВАНИЯ}

Работ выполнена с привлечением материальных средств ФГБУ «НМИЦ ПН им. В.М. Бехтерева» Минздрава России и ФГБУ «НМИЦ детской травматологии и ортопедии им. Г.И. Турнера» Минздрава России.

\section{СООТВЕТСТВИЕ ПРИНЦИПАМ ЭТИКИ}

Исследование проведено с соблюдением принципов современной биомедицинской этики, принятых ВОЗ, а также этических стандартов, разработанных в соответствии с Хельсинской декларацией BMA, и утверждено локальным этическим комитетом ФГБУ «НМИЦ ПН им. В.М. Бехтерева» (протокол № 75/17 от 27.06.2017 г.).

\section{ЛИТЕРАТУРА/REFERENCES}

1. Wittchen H.U., Jacobi F., Rehm J., Svensson G.A.M., Jönsson B., Olesen J., Allgulander C., Alonso J., Faravelli C., Fratiglioni L., Jennum P., Lieb R., Maercker A., van Os J., Preisig M., Salvador-Carulla L., Simon R., Steinhausen H.-C. The size and burden of mental disorders and other disorders of the brain in Europe 2010. Eur. Neuropsychopharmacol. 2011; 21(9): 655-79. doi: 10.1016/j.euroneuro.2011.07.018

2. Solanki R.K., Singh P., Munshi D. Current perspectives in the treatment of resistant schizophrenia. Indian J. Psychiatry. 2009 Oct-Dec; 51(4): 254-60. doi: 10.4103/00195545.58289

3. Thome J., Foley P., Riederer P. Neurotrophic factors and the maldevelopmental hypothesis of schizophrenic psychoses. Review article. J. Neural. Transm. (Vienna). 1998; 105: 85-100 doi: 10.1007/s007020050040

4. Bersani G., Iannitelli A., Fiore M., Angelucci F., Aloe L. Data and hypotheses on the role of nerve growth factor and other neurotrophins in psychiatric disorders. Med. Hypotheses. 2000; 55: 199-207 doi: 10.1054/mehy.1999.1044

5. Yamamori H., Hashimoto R., Ishima T., Kishi F., Yasuda Y., Ohi K., Fujimoto M., Umeda-Yano S., Ito A., Hashimoto K., Takeda M. Plasma levels of mature brainderived neurotrophic factor (BDNF) and matrix metalloproteinase-9 (MMP-9) in treatment-resistant schizophrenia treated with clozapine. Neurosci. Lett. 2013; 556: 3741. doi: 10.1016/j.neulet.2013.09.059

6. Иванова С.А., Бохан Н.А., Семке А.В. Основные гипотезы патогенеза шизофрении: экскурс в проблему. В книге: Бойко А.С., Бохан Н.А., Бунева В.Н., Ветлу- 

Корнетова Е.Г., Лосенков И.С., Олейчик И.В., Семке А.В., Смирнова Л.П., Узбеков М.Г., Федоренко О.Ю. Биологические маркеры шизофрении: поиск и клиническое применение. Новосибирск, 2017: 9-22. Ivanova S.A., Bokhan N.A., Semke A.V. The main hypotheses of the pathogenesis of schizophrenia: an excursion into the problem. In the book: Boyko A.S., Bokhan N.A., Buneva V.N., Vetlugina T.P., Zozulya S.A., Ivanova S.A., Klyushnik T.P., Kornetova E.G., Losenkov I.S., Oleichik I.V., Semke A.V., Smirnova L.P., Uzbekov M.G., Fedorenko O.Yu. Biological Markers of Schizophrenia: Search and Clinical Application Novosibirsk, 2017: 9-22 (in Russian).

7. Shimizu E., Hashimoto K., Watanabe H., Okamura N., Koike K., Komatsu N., Kumakiri C., Nakazato M., Shinoda N., Okada S.-I., Iyo M. Alterations of serum levels of brain-derived neurotrophic factor (BDNF) in depressed patients with or without antidepressants. Biol. Psychiatry. 2003; 54(1): 70-5. doi: 10.1016/s00063223(03)00181-1

8. Nieto R., Kukuljan M., Silva H. BDNF and schizophrenia: from neurodevelopment to neuronal plasticity, learn10.3389/fpsyt.2013.00045

9. Peng S., Li W., Lv L., Zhang Z., Zhan X. BDNF as a biomarker in diagnosis and evaluation of treatment for schizophrenia and depression. Discov. Med. 2018; 26(143): 127-136.

10. Левчук Л.А., Вялова Н.М., Михалицкая Е.В., Семкина А.А., Иванова С.А. Роль BDNF в патогенезе неврологических и психических расстройств. Современные проблемы науки и образования. 2018; 6. Levchuk L.A., Vyalova N.M., Mikhalitskaya E.V., Semkina A.A., Ivanova S.A. The role of BDNF in the pathoProblems of Science and Education. 2018; 6 (in Russian). URL: http://www.science-

education.ru/ru/article/view?id=28267

11. Toyooka K., Asama K., Watanabe Y., Muratake T., Takahashi M., Someya T., Nawa H. Decreased levels of schizophrenic patients. Psychiatry. Res. 2002; 110: 249257 doi: 10.1016/s0165-1781(02)00127-0

12. Колесниченко Е.В., Барыльник Ю.Б., Голимбет В.Е., Бородулин В.Б., Федотов Э.А. Исследование влияния полиморфизма Val66Met гена BDNF на сывороточный уровень мозгового нейротрофического фактора у больных параноидной шизофренией. Современные проблемы науки и образования. 2014; 6. Kolesnichenko E.V., Barylnik Yu.B., Golimbet V.E., Borodulin V.B., Fedotov E.A. Investigation of the effect of Val66Met polymorphism of the BDNF gene on the serum level of cerebral neurotrophic factor in patients with paranoid schizophrenia. Modern Problems of Science and Educa- гина Т.П., Зозуля С.А., Иванова С.А., Клюшник Т.П., ing, and memory. Front. Psychiatry. 2013; 4:45. doi: genesis of neurological and mental disorders. Modern brain-derived neurotrophic factor in serum of chronic

tion. 2014; 6 (in Russian). URL: http://www.scienceeducation.ru/ru/article/view?id=15618

13. Ursini G., Cavalleri T., Fazio L., Popolizio T., Caforio G., Blasi G., Riva M.A., De Blasi A., Chiariotti L., Bollati V., Bertolino A. BDNF rs6265 methylation and genotype interact on risk for schizophrenia. Epigenetics. 2016; 11(1): 11-23. doi: 10.1080/15592294.2015.1117736

14. Zakharyan R., Boyajyan A. Brain-derived neurotrophic factor blood levels are decreased in schizophrenia patients and associate with rs6265 genotypes. Clin. Biochem. 2014; 47(12): 1052-1055. doi:10.1016/j.clinbiochem.2014.03.021

15. Lee B.H., Kim Y.K. Increased plasma brain-derived neurotropic factor, not nerve growth factor-Beta, in schizophrenia patients with better response to risperidone treatment. Neuropsychobiology. 2009; 59(1): 51-8. doi: $10.1159 / 000205518$

16. Carlo D.P., Punzi G., Ursini G. Brain-derived neurotrophic factor and schizophrenia. Psychiatr. Genet. 2019; 29(5): 200-210. doi: 10.1097/YPG.0000000000000237

17. Martinotti G., Ricci V., Nicola D.M., Caltagirone C., Bria P., Angelucci F. Brain-derived neurotrophic factor and electroconvulsive therapy in a schizophrenic patient with treatment-resistant paranoid-hallucinatory symptoms. $J$. ECT. 2011; 27(1): doi:10.1097/YCT.0b013e318205e1c0

18. Li J., Ye F., Xiao W., Tang X., Sha W., Zhang X., Wang J. Increased serum brain-derived neurotrophic factor levels following electroconvulsive therapy or antipsychotic treatment in patients with schizophrenia. Eur. Psychiatry. 2016; 36: 23-8 doi: 10.1016/j.eurpsy.2016.03.005

19. Li J., Zhang X., Tang X., Xiao W., Ye F., Sha W., Jia Q. Neurotrophic factor changes are essential for predict electroconvulsive therapy outcome in schizophrenia. Schizophr. Res. 2020; S0920-9964(19)30470-0 (online ahead of print). doi:10.1016/j.schres.2019.10.035

20. Jaffe R. The practice of electroconvulsive therapy: recommendations for treatment, training and privileging. A task force report of the American Psychiatric Association. 2nd edition Washington, D.C., APA, 2001: 355.

21. Kay S.R., Fiszbein A., Opler L.A. The positive and negative syndrome scale (PANSS) for schizophrenia. Schizophr. Bull. 1987; 13(2): 261-276. DOI: $10.1093 /$ schbul/13.2.261

22. Kinon B.J., Chen L., Ascher-Svanum H., Stauffer V.L., Kollack-Walker S., Zhou W., Kapur S., Kane J.M. Early response to antipsychotic drug therapy as a clinical marker of subsequent response in the treatment of schizophrenia. Neuropsychopharmacology. 2010; 35(2): 581-590. doi: 10.1038/npp.2009.164

Поступила в редакцию 02.04.2020 Утверждена к печати 01.06.2020

Иванов Михаил Владимирович - д.м.н., профессор, руководитель отделения биологической терапии психически больных ФГБУ «Национальный медицинский исследовательский центр психиатрии и неврологии им. В.М. Бехтерева».profmikhailivanov@gmail.com

Зубов Дмитрий Сергеевич - м.н.с. отделения биологической терапии психически больных ФГБУ «Национальный медицинский исследовательский центр психиатрии и неврологии им. В.M. Бехтерева». dszubov@yandex.ru

Хальчицкий Сергей Егорович - к.б.н., руководитель генетической лаборатории ФГБУ «Национальный медицинский исследовательский центр детской травматологии и ортопедии им. Г.И. Турнера». s_khalchitski@mail.ru

Согоян Марина Ваниковна - научный сотрудник генетической лаборатории ФГБУ «Национальный медицинский исследовательский центр детской травматологии и ортопедии им. Г.И. Турнера». sogoyanmarina@mail.ru 
Щедрина Людмила Викторовна - канд. биол. наук, с.н.с. ФГБУ «Национальный медицинский исследовательский центр психиатрии и неврологии им. В.М. Бехтерева».

Зубов Дмитрий Сергеевич, dszubov@yandex.ru

UDC 616.895.8:615.214:615.869:575.174.015.3:632.95.025

For citation: Zubov D.S., Ivanov M.V., Khalchitsky S.E., Sogoyan M.V., Shchedrina L.V. The relationship of rs6265 gene polymorphism and serum BDNF level in patients with therapeutically resistant schizophrenia in the dynamics of the treatment process. Siberian Herald of Psychiatry and Addiction Psychiatry. 2020; 2 (107): 60-66. https://doi.org/10.26617/1810-3111-2020-2(107)-60-66

\title{
The relationship of rs6265 gene polymorphism and serum BDNF level in patients with therapeutically resistant schizophrenia in the dynamics of the treatment process
}

\author{
'Zubov D.S., ${ }^{1}$ Ivanov M.V., ${ }^{2}$ Khalchitsky S.E., \\ 'Sogoyan M.V., 'Shchedrina L.V. \\ ${ }^{1}$ Federal State Budgetary Institution "V.M. Bekhterev National Medical Research Center of Psychiatry and Neurology" \\ Bekhterev Street 3, 192019, Saint-Petersburg, Russian Federation \\ ${ }^{2}$ H. Turner National Medical Research Center for Children's Orthopedics and Trauma Surgery \\ Parkovaya Street 64-68, Pushkin, 196603, Saint-Petersburg, Russian Federation
}

\begin{abstract}
The article presents data on the found relationship of the RDN6265 polymorphism of the BDNF gene, serum BDNF level, and clinical and therapeutic parameters in patients with paranoid schizophrenia with the presence of therapeutic resistance. The object of the study are patients with diagnosed paranoid schizophrenia, divided into two groups according to the nature of the intervention: combination of electroconvulsive therapy with psychopharmacotherapy $(\mathrm{EC} \mathrm{T}+\mathrm{PFT})$ and exclusively PFT. The results of the study indicate a significantly higher therapeutic response and a more pronounced reduction in psychopathological symptoms in patients of the combination therapy group (ECT + PFT). At the same time, it was found that serum BDNF tend to increase more when using the combined therapy option (ECT + PFT), mainly in patients with ValMet and MetMet genotypes. The initial results obtained will be further refined in the course of subsequent larger studies.
\end{abstract}

Keywords: brain-derived neurotrophic factor BDNF, rs6265 Val66Met, electroconvulsive therapy (ECT), psychopharmacotherapy, therapeutically resistant schizophrenia, therapeutic resistance, PANSS scale.

Received April 02.2020

Accepted June 01.2020

Ivanov Mikhail V. - MD, Professor, Head of the Department of Biological Therapy of Mental Patients, Federal State Budgetary Institution "National Medical Research Center for Psychiatry and Neurology named after V.M. Bekhterev" of the Ministry of Health of Russia, Saint-Petersburg, Russian Federation. profmikhailivanov@gmail.com

Zubov Dmitriy S. - junior researcher of the Department of Biological Therapy of Mental Patients, Federal State Budgetary Institution "National Medical Research Center for Psychiatry and Neurology named after V.M. Bekhterev" of the Ministry of Health of Russia, Saint-Petersburg, Russian Federation. dszubov@yandex.ru

Khalchitsky Sergey Y. - PhD, Head of the Genetic Laboratory, H. Turner National Medical Research Center for Children's Orthopedics and Trauma Surgery, Saint-Petersburg, Russian Federation. s_khalchitski@ mail.ru

Sogoyan Marina V. - researcher of the Genetic Laboratory, H. Turner National Medical Research Center for Children's Orthopedics and Trauma Surgery, Saint-Petersburg, Russian Federation. sogoyanmarina@mail.ru

Shchedrina Ludmila V. - PhD, Senior Researcher, Federal State Budgetary Institution "National Medical Research Center for Psychiatry and Neurology named after V.M. Bekhterev" of the Ministry of Health of Russia, Saint-Petersburg, Russian Federation. 